\title{
Growth Performance and Fatty Acid Profiles of Ducks Fed a Diet Supplemented with Aronia (Aronia Melanocarpa) Powder
}

Technical Note

-Author(s)

\section{Lee GD' \\ Shin $\mathrm{JH}^{\prime \prime}$ \\ Choi IH"II}

Department of Food Science and Biotechnology, Joongbu University, Geumsan-gun, 32713, South Korea

Department of Food and Nutrition, Joongbu University, Geumsan-gun, 32713, South Korea

III Department of Companion Animal \& Animal Resources Science, Joongbu University, Geumsan-gun, 32713, South Korea

Gee-Dong, Lee and Jung-Hee, Shin contributed equally to this study as first author.

\section{Mail Address}

Corresponding author e-mail address In Hag, Choi

Department of Companion Animal \& Animal Resources Science, Joongbu University,

Geumsan-gun, 32713, South Korea.

Tel: $\quad+82-10-5527-7422$

Email: wicw@chol.com

\section{EKeywords}

Aronia powder, Growth performance, Fatty acid profiles.

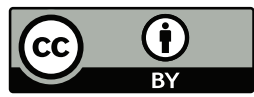

Submitted: 01/September/2017 Approved: 31/October/2017

\section{ABSTRACT}

The present study evaluated the effects of aronia powder on growth performance and fatty acid profiles of ducks. A total of 90 ducks (oneday-old pekin, 48 males and 42 females) were distributed according to a completely randomized design into two treatments (control and 1\% aronia powder) with 3 replicates of 15 birds per pen for $42 \mathrm{~d}$. Apart from the feed:gain ratio, the other growth performance parameters, including initial body weight, final body weight, weight gain, and feed intake, did not differ significantly between treatments ( $p>0.05$ ). In addition, there was no significant difference $(p>0.05)$ in fatty acid profiles between treatments. However, oleic acid (C18:1), linoleic acid (C18:2), and polyunsaturated fatty acid (PUFA) were significantly different $(p<0.05)$ between treatments. Our results revealed that feeding ducks with $1 \%$ aronia powder improved the weight gained and the feed:gain ratio, but did not affect the fatty acid profiles of duck breast meat.

\section{INTRODUCTION}

Aronia (Aronia melanocarpa) is a sustainable crop that can grow to a height of 2-3 m, producing as many as 30 small white umbels of flowers between May and June in the eastern parts of North America and East Canada (Bräunlich, 2014). It has a long tradition in European and North American folk medicine, and it is believed to have a wide range of potential therapeutic effects. Three species of Aronia are known: red chokeberry (Aronia arbutifolia), black chokeberry ( $A$. melanocarpa), and purple chokeberry (A. prunifolia), a hybrid between A. arbutifolia and A. melanocarpa (Šnebergrovă et al., 2014). It is a well-known natural antioxidant with procyanidins (the major class of polyphenolic compounds) and anthocyanins (the second largest group of phenolic compounds), and is attracting more and more attention owing to not only its high antioxidant values, but also its antimutagenic, hepatoprotective, and anti-diabetes effects (Kulling \& Rawel, 2008; Bräunlich, 2014). For example, only this study has reported an antioxidant effect in poultry, especially on decreasing lipid peroxidation using chokeberry pomace and enhancing the activity of enzymes which also contribute to the antioxidant defense system (Loetscher et al., 2013).

Nutritionally, the characteristic composition of aronia berries provides low calories (84 kcal per $100 \mathrm{~g}$ ), low sugar (19 g per $100 \mathrm{~g}$ ), and low fat $(0.13 \mathrm{~g}$ per $100 \mathrm{~g})$. They contain pectin (between 0.3 and $0.6 \%)$, protein ( $1.4 \mathrm{~g}$ per $100 \mathrm{~g})$, vitamins B groups, vitamin C (13-270 $\mathrm{mg} / \mathrm{kg}$ ), and minerals (4.4-5.8 $\mathrm{g} / \mathrm{kg}$ as ash value) (Kulling \& Rawel, 2008; Aurand, 2010). This implies that the proximate composition of aronia berries, which is similar to many other high-nutrient fruits, has characteristics that can benefit the developer (Aurand, 2010). 
According to Kulling \& Rawel (2008), there has been only limited use of these berries in the food industry (large scale juice and fruit nectar production) because of their extreme sourness and somewhat unpleasant astringent taste. Therefore, although aronia can be used to make syrup, juice, jellies, jams, wines, and tea, consumers often prefer to blend it with other, more flavorful ingredients (Šnebergrovâ et al., 2014). Currently, there are no data in the literature about the use and effects of aronia powder on ducks. Most of the reported pharmacological activities of aronia in animals come from tests on rats. Therefore, the aim of the present study was to evaluate the growth performance and fatty acid profiles of ducks that were fed diets that included aronia powder.

\section{MATERIALS AND METHODS}

All experimental procedures were conducted in accordance with the animal care guidelines of animal policy approved by the Gilhong farm committee (Geochang, South Korea). Ninety ducks (one-dayold pekin, 48 males and 42 females) were distributed according to a completely randomized design into two treatments (control and 1\% aronia powder (T1) with 3 replicates of 15 birds per pen. First, aronia powder was obtained by freeze drying process of aronia fruit for 1 week. Then, the freeze-dried aronia fruits were ground through a 1-mm sieve before addition to the basal diet. Ducks were housed in floor pens $(2.0 \times 1.5 \mathrm{~m} ; 8 \mathrm{~cm}$ of litter comprising rice hulls and duck manure) and provided 23 h-1 h light-dark cycle throughout a 42day experimental period. Each pen was supplied with a single feed trough and 6 nipples with a nipple watering line. Ducks were given a 2-phase feeding regimen consisting of a starter diet (1 to $21 \mathrm{~d}$, containing $21 \%$ crude protein, $21 \%$ crude protein, $2.5 \%$ crude fat, $8 \%$ crude fiber, $9 \%$ crude ash, $0.40 \% \mathrm{Ca}$, and $1.50 \% \mathrm{P}$ ) and a finisher diet (22 to 42 days, containing 17\% crude protein, $2.5 \%$ crude fat, $8 \%$ crude fiber, $9 \%$ crude ash, $0.40 \% \mathrm{Ca}$, and $1.0 \% \mathrm{P}$ ). Feed and water were available to the ducks ad libitum. Temperature was maintained at $33^{\circ} \mathrm{C}$ for the first $14 \mathrm{~d}$ and then reduced as the ducks progressed in age with a final temperature of $20^{\circ} \mathrm{C}$ at $42 \mathrm{~d}$ of age. Automatically controlled air inlets and exhaust fans located along the side walls were used for ventilation and relative humidity.

For growth performance, ducks were weighed at 0 and $42 \mathrm{~d}$ of age, and weight gain was calculated as the difference between the final and initial duck body weight. Feed intake was also recorded at each feed change interval during the experimental period.
Feed:gain ratio was calculated as the feed intake per gram of body weight gained.

At the end of the experimental period, 18 ducks (For each treatment, three birds were sampled from each of the three pens) were taken out of the rearing room and moved in crates that were immediately brought to the slaughterhouse. Feed withdrawal was extended for $12 \mathrm{~h}$ before slaughter. Ducks were electrically stunned and slaughtered by cutting the neck. After bleeding, the carcasses were immersed in hot water $\left(60^{\circ} \mathrm{C}\right.$ for $\left.2 \mathrm{~min}\right)$ and then plucked, eviscerated to obtain breast meat. All skin, subcutaneous fat, and visible connective tissues were completely removed from the breast meat before evaluation for fatty acid parameters. Samples were immediately kept for $24 \mathrm{~h}$ at $4{ }^{\circ} \mathrm{C}$ for further analyses.

Fatty acid was extracted using a chloroform/ methanol (2:1, vol/vol) mixture according to Folch et al. (1957). The fatty acid methyl esters (FAME) were analyzed using gas chromatography (GA-17A, Shimadzu, Tokyo, Japan) equipped with a flameionization detector and a CP-Sil88 column $(100 \mathrm{~m}$ $\times 0.25 \mathrm{~mm} \times 0.2 \mu \mathrm{m}$; Chrompack, Middelburg, the Netherlands). The identification of the fatty acid peak (C14:0 to 24:1) was carried out by comparing with peak retention times of FAME standard mixtures (Sigma-Aldrich, Germany). Fatty acid concentrations were expressed as a percentage of each individual fatty acid relative to total fatty acids.

Data analysis was performed using the general linear model procedure (SAS Institute Inc., 2002) with the pen used as the experimental unit. The independentsamples t-test was used for comparison of means between two samples at a probability level of $<0.05$.

\section{RESULTS AND DISCUSSION}

The effects of dietary supplementation of aronia powder on growth performance are shown in Table 1. Except for feed:gain ratio, none of the other growth performance parameters, including initial body weight, final body weight, weight gain, or feed intake were affected ( $p>0.05)$. Although our results showed no statistically significant effect on these growth parameters, they suggest that dietary supplementation of aronia powder (T1) improves weight gain. For example, in a study conducted using nettle (Urtica dioica) to improve growth performance of broiler, it is reported that the production of endogenous secretion in the small intestinal mucosa, pancreas, and liver is stimulated by nettle (Safamehr et al., 2012). Moreover, Loetscher et al. (2013) observed no obvious effect on growth performance (ADFI, ADG, and feed conversion 
Table 1 - Effects of dietary aronia powder supplementation on growth performance of ducks after 6 wk

\begin{tabular}{|c|c|c|c|}
\hline \multirow{2}{*}{ Item } & \multicolumn{2}{|c|}{ Treatment $^{1}$} & \multirow{2}{*}{ Significance } \\
\hline & Control & $\mathrm{T} 1$ & \\
\hline Initial body weight (g) & $47.36 \pm 0.33$ & $47.19 \pm 0.47$ & $\mathrm{NS}^{2}$ \\
\hline Final body weight (g) & $3,602.52 \pm 30.00$ & $3,655.98 \pm 48.22$ & NS \\
\hline Weight gain (g) & $3,555.16 \pm 29.67$ & $3,608.79 \pm 47.75$ & NS \\
\hline Feed intake (g) & $6,709.15 \pm 39.26$ & $6,625.97 \pm 42.04$ & NS \\
\hline Feed:gain ratio & $1.89 \pm 0.02$ & $1.84 \pm 0.03$ & * \\
\hline
\end{tabular}

${ }^{1}$ Control: no treatment; $\mathrm{T1}: \mathrm{T} 1=$ basal diets $+1 \%$ aronia powder. ${ }^{2} \mathrm{NS}$ : not significant. ${ }^{*} p<0.05$.

ratio) of the broilers supplemented with rosemary leaves, rosehip fruits, chokeberry pomace, and the entire nettle during the entire experimental period. They explained the decreased number of replicates in these traits. In the study by Al-Kassie (2009), supplementing two plant extracts containing thyme and cinnamon (at the levels of $200 \mathrm{ppm}$ ) has been shown to improve feed intake, body weight gain and feed conversion ratios in broiler.

In the present study, the possible mechanisms of action of aronia powder in the animal for improving growth performance include increased digestibility, nutrient absorption, and the effect of bioactive compounds (phenolic constituents) present in aronia. This suggested as hypothesis that there is evidence from the present study for a bioactive effect of aronia powder in ducks. However, the results reported do not seem to intuitively reflect what mechanism is causing the improved growth performance. According to Loetscher et al. (2013), it is important to know whether or not this is related to any unfavorable effects on performance for prevention of the adoption of this measure in broiler production practice when choosing strategic supplementation of various herbs. To the best of our knowledge, the present study is the first to investigate the effects of aronia powder on growth performance of ducks.

Fatty acid compositions of duck breast meats are summarized in Table 2. There were no significant differences $(p>0.05)$ in fatty acid profiles between

Table 2 - Effects of dietary aronia powder supplementation on fatty acid profiles in duck breast meat after 6 wk

\begin{tabular}{|c|c|c|c|}
\hline \multirow{2}{*}{ Fatty acids (\%) } & \multicolumn{2}{|c|}{ Treatment $^{1}$} & \multirow{2}{*}{ Significance } \\
\hline & & & \\
\hline Myristic acid (C14:0) & $0.80 \pm 0.30$ & $0.88 \pm 0.16$ & NS \\
\hline Myristoleic acid (C14:1) & $19.82 \pm 0.89$ & $18.77 \pm 0.24$ & NS \\
\hline Palmitic acid (C16:0) & $0.20 \pm 0.01$ & $0.20 \pm 0.01$ & NS \\
\hline Palmitoleic acid (C16:1) & $0.10 \pm 0.02$ & $0.11 \pm 0.02$ & NS \\
\hline Stearic acid (C18:0) & $17.17 \pm 0.56$ & $16.87 \pm 0.66$ & NS \\
\hline Oleic acid (C18:1) & $21.78 \pm 2.72$ & $26.19 \pm 1.98$ & * \\
\hline Linoleic acid (C18:2) & $18.07 \pm 0.17$ & $16.51 \pm 0.30$ & * \\
\hline$\alpha$-linolenic acid (C18:3n-3) & $0.37 \pm 0.02$ & $0.36 \pm 0.02$ & NS \\
\hline Arachidic acid (C20:0) & $0.19 \pm 0.01$ & $0.17 \pm 0.02$ & NS \\
\hline Eicosenoic acid (C20:1) & $0.39 \pm 0.01$ & $0.41 \pm 0.03$ & NS \\
\hline Eicosadienoic acid (C20:2) & $0.57 \pm 0.04$ & $0.52 \pm 0.05$ & NS \\
\hline Eicosatrienoic acid (C20:3n-6) & $1.50 \pm 0.23$ & $1.18 \pm 0.17$ & NS \\
\hline Arachidonic acid (C20:4) & $0.17 \pm 0.07$ & $0.09 \pm 0.01$ & NS \\
\hline Behenic acid (C22:0) & $1.34 \pm 0.08$ & $1.36 \pm 0.13$ & NS \\
\hline Getoleic acid (C22:1) & $13.59 \pm 1.16$ & $12.55 \pm 0.66$ & NS \\
\hline Docosadienoic acid (C22:2) & $0.17 \pm 0.01$ & $0.21 \pm 0.01$ & NS \\
\hline Adrenic Acid (C22:4) & $1.56 \pm 0.29$ & $1.52 \pm 0.14$ & NS \\
\hline Lignoceric (C24:0) & $2.08 \pm 0.07$ & $1.96 \pm 0.15$ & NS \\
\hline Eicosapentaenoic (C20:5n-3, EPA) & $0.03 \pm 0.01$ & $0.06 \pm 0.02$ & NS \\
\hline Docosapentaenoic acid (C22:5n-3, DPA) & $0.02 \pm 0.01$ & $0.02 \pm 0.00$ & NS \\
\hline Docosahexaenoic (C22:6n-3, DHA) & $0.08 \pm 0.02$ & $0.07 \pm 0.01$ & NS \\
\hline Saturated fatty acid (SFA) & $21.78 \pm 0.81$ & $21.44 \pm 0.92$ & NS \\
\hline Mono unsaturated fatty acid (MUFA) & $55.69 \pm 1.29$ & $58.03 \pm 1.26$ & NS \\
\hline Poly unsaturated fatty acid (PUFA) & $22.53 \pm 0.62$ & $20.53 \pm 0.64$ & * \\
\hline PUFA/SFA & $1.04 \pm 0.03$ & $0.96 \pm 0.04$ & NS \\
\hline
\end{tabular}

${ }^{1}$ Control: no treatment; $\mathrm{T} 1: \mathrm{T} 1=$ basal diets $+1 \%$ aronia powder. ${ }^{2} \mathrm{NS}$ : not significant. ${ }^{*} p<0.05$. 
treatments. However, oleic acid (C 18:1), linoleic acid (C18:2), and polyunsaturated fatty acid (PUFA) differed significantly $(p<0.05)$ between treatments. In addition, individual saturated fatty acid and total saturated fatty acid (SFA) between treatments is similar. Although none of the fatty acid profiles of duck breast meats changed, feeding aronia powder at a level of $1 \%$ in the diet tended to higher the monounsaturated fatty acid (MUFA), or decrease the polyunsaturated fatty acid (PUFA) content in the breast meat when compared to that in the control group. These results indicate that aronia has a minor positive effect on MUFA rather than PUFA in fat metabolism. This is in contrast to previous studies from Kamboh \& Zhu (2013) which found that increasing levels of dietary bioflavonoids improved $(p<0.05)$ the proportion of total polyunsaturated fatty acids and the ratio of polyunsaturated fatty acids to saturated fatty acids in broiler breast muscles. Likewise, Marcinčáková et al. (2011) reported that for broiler breast meat, the proportion of monounsaturated fatty acids was decreased and polyunsaturated fatty acids (PUFA) proportion was increased by feeding of lemon balm (Melissa officinalis L.) and combination of hawthorn (Crataegus oxyacantha L.) and yarrow (Achillea millefolium L.) compared with the control group $(p<0.05)$

In terms of health, the fatty acid composition of meat products is regarded as an important parameter of meat quality and is affected by the fatty acid composition of the feed, as described in Cortinas et al. (2005). However, our data did not support results from an earlier study, which suggests that increased PUFA:SFA ratio in meat might be due to the protection of dietary antioxidants that act as electron donors for reduction of some unsaturated fatty acids (Chikunya et al., 2004) or radical scavenging associated with both activity enhancement and protection of enzymes such as peroxide dismutase and glutathione reductase (Law et al., 1999). In conclusion, feeding aronia powder at a level of $1 \%$ in the duck diet improved the weight gained and the feed:gain ratio, when compared to the control. However, there were no remarkable differences in fatty acid profiles of breast meat.

\section{REFERENCES}

Al-Kassie GAM. Influence of two plant extracts derived from thyme and cinnamon on broiler performance. Pakistan Veterinary Journal 2009;29:169-173

Aurand T. Aronia, the richest north american fruit. A white paper on the benefits of aronia berries; 2010. Available from: https://issuu.com/ milnefruit/docs/mfp_aronia_white_paper1509f.

Bräunlich M. Bioactive constituents in aronia berries [thesis]. Oslo (NRU): Department of Pharmaceutical Chemistry School of Pharmacy University of Oslo; 2014.

Chikunya S, Demirel G, Enser M, Wood JD, Wilkinson RG, Sinclair LA. Biohydrogenation of dietary n-3 PUFA and stability of ingested vitamin $E$ in the rumen, and their effects on microbial activity in sheep. British Journal of Nutrition 2004;91:539-550.

Cortinas L, Barroeta A, Villaverde C, Galobart J, Guardiola F, Baucells MD. Influence of the dietary polyunsaturation level on chicken meat quality: lipid oxidation. Poultry Science 2005;84:48-55.

Folch J, Lees M, Sloane-Stanley GH. A simple method for the isolation and purification of total lipides from animal tissues. Journal of Biological Chemistry 1957;226:497-509.

Kamboh AA, Zhu WY. Effect of increasing levels of bioflavonoids in broiler feed on plasma anti-oxidative potential, lipid metabolites, and fatty acid composition of meat. Poultry Science 2013;92:454-461.

Kulling SE, Rawel HM. Chokeberry (Aronia melanocarpa) - a review on the characteristic components and potential health effects. Planta Medica 2008; $74: 1625-1634$.

Law A, Wu J, Zeng LH, Wu TW. Aortic endothelial cells damaged by a nitric oxide donor and protected by flavonoids. Life Science 1999;64:199 204.

Loetscher Y, Kreuzer M, Messikommer RE. Oxidative stability of the meat of broilers supplemented with rosemary leaves, rosehip fruits, chokeberry pomace, and entire nettle, and effects on performance and meat quality. Poultry Science 2013;92:2938-2948.

Marcinčáková D, Čertík M, Marcinčák S, Popelka P, Šimková J, Klempová $\mathrm{T}$, et al. Effect of dietary supplementation of Melissa officinalis and combination of Achillea millefolium and Crataegus oxyacantha on broiler growth performance, fatty acid composition and lipid oxidation of chicken meat. Italian Journal of Animal Science 2011:4:65-170.

Safamehr A, Mirahmadi M, Nobakht A. Effect of nettle (Urtica dioica) medicinal plant on growth performance, immune responses, and serum biochemical parameters of broiler chickens. International Research Journal of Applied and Basic Sciences 2012;3:721-728.

SAS Institute. SAS/STAT user's guide: version 8.2. Cary: SAS Institute; 2002

Šnebergrová J, Čížková H, Neradová E, Kapci B, Rajchl A, Voldřich M. Variability of characteristic components of aronia. Czech Journal of Food Science 2014;32:25-30. 